\title{
Measuring The Impact of Risk On LCOE(Levelized Cost of Energy) In Geothermal Technology
}

\section{Antony Kipkirui Langat}

Kenya Electricity Generating Company

\section{Yongbeum Yoon}

Department of Energy Policy

Soojin Park ( $\nabla$ sugini1144@gmail.com )

Department of Energy Policy https://orcid.org/0000-0003-1564-5760

\section{Research}

Keywords: geothermal technology, Levelized cost of energy, Certainty equivalent, Weighted average cost of capital (WACC), Monte Carlo Simulation, Project valuation

Posted Date: September 20th, 2021

DOI: https://doi.org/10.21203/rs.3.rs-869061/v1

License: (c) (1) This work is licensed under a Creative Commons Attribution 4.0 International License. Read Full License 


\title{
Measuring the Impact of Risk on LCOE(Levelized Cost of Energy) in Geothermal Technology
}

\author{
Antony Langat ${ }^{a}$, Yongbeum Yoon ${ }^{b}$, Soojin Park ${ }^{* c}$ \\ ${ }^{a}$ Department of Energy Policy and Engineering, KEPCO International Nuclear Graduate School \\ ${ }^{b}$ Associate Professor of epartment of Energy Policy and Engineering, KEPCO International Nuclear Graduate School \\ *c Corresponding Author, Assistant Professor of Department of Energy Policy and Engineering, KEPCO International Nuclear Graduate \\ School, 658-91 Haemaji-ro, Seosaeng-Myeon, Ulju-gun, Ulsan 45014, Korea; e-mai: sugini1144@gmail.com; Tel.: +82-10-7357-7670
}

\author{
A R T ICLE INFO \\ Article history: \\ Received 00 December \\ 00 \\ Received in revised \\ form 00 January 00 \\ Accepted 00 February \\ 00
Keywords:
geothermal technology
Levelized cost of energy
Certainty equivalent
Weighted average cost
of capital (WACC)
Monte Carlo Simulation
Project valuation

\begin{abstract}
A B S T R A C T
Geothermal technology has a high level of uncertainty and, thus, requires thorough risk analysis for economic decisions. The Levelized Cost of Energy (LCOE) is a basic economic analysis widely used in determining an investment or energy mix. Many reputable institutions and government agencies provide LCOE, to which they apply different levels of discount rates to reflect project risk. It is a proxy for the Weighted Average Cost of Capital (WACC). Theoretically, determining whether using a higher discount rate for a risky project is appropriate in calculating LCOE has not been scrutinized. The purpose of this paper is to propose a certainty equivalent method of LCOE as an alternative way of reflecting risk. We present a theoretical background and formula based on the utility theory, improving the probabilistic LCOE estimation methodology of previous studies. We also perform scenario analysis to show how the LCOE with certainty equivalent model moves over the change of risk in major input factors, whereas traditional LCOE does not. Additionally, we suggest that the traditional LCOE should be used prudently, recognizing it can distort the result when an individual project has a different level of risk from the industry average.
\end{abstract}

\section{Introduction}

Geothermal technology is a renewable energy source that is the best substitute for those regions with considerable volcanic storage underground, and it is not dependent on the weather. This resource can be exploited from underneath the earth's surface reservoirs, containing high-temperature rocks saturated with hot brine or steam by drilling wells of approximately two kilometers below the earth's surface (Regenspurg \& Schäfer, 2017). The hot water and steam are then extracted from the underground reservoirs using pipes up to a geothermal power plant, where they are used to drive turbines coupled to electric generators to produce electricity.

There are many risks associated with geothermal projects that currently deter private sector investors from venturing into this energy source (Laura Wendell et al., 2018). Surface exploratory and drilling is among the highest risk associated with geothermal (Kolditz et al., 2013). Geothermal well viability is only proven after drilling has been completed. Well output is another risk that can significantly affect projected capital costs required and impact the feasibility of a geothermal power project. Although geothermal technology has a high capacity factor, wells drying out is a risk that prevents the plant from generating the maximum electricity required, affecting 
the projected revenue (The World Bank et al., 2014). The high level of risk profile in geothermal technology requires a thorough risk analysis and reflection concerning economic analysis.

The Levelized Cost of Energy (LCOE) is often recommended to determine the competitiveness of an energy mix (EIA, 2020b). It computes the unit cost of energy from the present value of costs incurred over the lifetime of the plant. Many reputable institutions and government agencies, such as the UK Government Department for Business, U.S. EIA, OECD IEA, and IRENA, produce LCOE data. Many of them apply different levels of discount rates to reflect the level of project risk, which may be regarded as a surrogate for the Weighted Average Cost of Capital (WACC). For example, the HM Government Department for Business applies a discount rate of 8.9\% for offshore wind projects and $7.8 \%$ for gas turbine projects, which are in agreement with the range for the cost of capital estimated by the Competition and Market Authority for integrated generation companies (AlderseyWilliams \& Rubert, 2019). The U.S. EIA calculated LCOE values by applying the real WACC of $4.3 \%$, which corresponds to $6.6 \%$ of the after-tax nominal rate for plants entering services in 2025 (EIA, 2020b). The IRENA applied a 7.5\% discount rate for OECD countries and China, and 10\% elsewhere (IRENA, 2019).

However, whether using a higher WACC for a risky project is appropriate in calculating LCOE is not fully understood. For example, Manhos (2013) argued that the most appropriate rate to use in comparing technologies is the risk-free rate.

Further criticism may be raised based on Beedles (1978) (Beedles, 1978) and Lewellen (1977) (Lewellen et al., 1977). He showed that a lower discount rate should be used for riskier projects if the cash flow is negative.

Aswath (2007) explains, "When cash flows are negative, using a higher discount rate will have the perverse impact of reducing their present value and perhaps increasing the aggregate value of the asset" (Damodaran, 2007). The numerator in the LCOE is the discounted life-cycle cost, which is purely negative cash flow. Thus, we can infer that there may be something wrong if we increase the discount rate for risky projects.

As a result, determining how to reflect project risk properly in the LCOE calculation is among the most important concerns for geothermal technology. The purpose of this paper is to propose an alternative way to reflect risk in LCOE and to compare the result with traditional methods used in geothermal technology. Instead of the discounting method with WACC, we propose a straightforward way to estimate and incorporate risk into the LCOE via a certainty equivalent method. We apply the probabilistic method with a Monte-Carlo Simulation to measure the certainty equivalent value of the LCOE. Additionally, we use research-based input data and distributions to draw a realistic LCOE estimation result for geothermal technology.

The rest of this paper contains the following five sections: literature review, research methodology, input data, case analysis, and conclusion.

\section{Literature Review}

Numerous researchers have studied the weaknesses and technical improvements concerning the LCOE formula. However, few papers have covered the topic of discount rate in the LCOE. One prominent paper focused on the discount rate of the LCOE is Manzhos (2013) (Manzhos, 2013), who concluded that different rates should be used between borrowing and discount rates in assessing the LCOE. He suggested that a risk-free rate should be used to discount when assessing and comparing different technologies. He assumed the life-cycle project cost to be financed, using a sequence of bonds that pay a principal and accrued interest at the end of the project. He also drew the present value of the future bond payment equation, which value comprises the numerator part of the LCOE formula. Using this equation, he showed that the interest rate should differ from the discount rate to avoid the LCOE equation being independent of the interest rate. Further, he showed that the interest rate should become a risk-free rate based on the arbitrage transaction process. His approach increases the future value (in absolute terms) of the life-cycle cost proportional to the interest rate, which reflects the level of project risk. The absolute values of risky cash flows are evaluated as being larger, because the cost is negative cash flow. Therefore, it yields a similar outcome with the certainty equivalent cash flow method, reflecting the project risk directly to the corresponding cash flows. 
Sklar-Chik et al. (2016) argued that the traditional LCOE does not consider inflation (Sklar-Chik et al., 2016). Including inflation may produce contrary results between different energy technologies, resulting from different types of expenditures.

Other relevant research on the discount rate of the LCOE includes Aldersey et al. (2019) (Aldersey-Williams \& Rubert, 2019), who sought a theoretical foundation of LCOE by comparing the alternative costs of energy metrics. The LCOE weaknesses centered on the discount rate, inflation effects, and sensitivity of results to uncertainty in future commodity costs. The authors maintained that the HM Government Department for Business used the 'hurdle rate,' which may have skewed the LCOE estimation due to an inappropriate reflection of individual projects' risk in a particular way. They suggested applying a higher discount rate to gas turbines, considering the high level of historical commodity price volatility. Conversely, a lower discount rate should be applied to wind power due to technological stabilization. They also provided a comparison of the LCOE estimation results between traditional and probabilistic methods, concluding that the latter could offer a richer analysis with which to compare technologies. However, the authors did not propose an alternative way to determine an optimal discount rate, reflecting an individual project's risk or another framework to consider project risk, rather than riskbased discounting.

Other streams of research introduced a probabilistic approach, using a Monte-Carlo simulation to calculate the LCOE using a specific distribution of input variables and estimating the most probable value or statistical range of the LCOE under a pre-determined confidence level.

Geissmann et al. (2017) utilized a probabilistic model that accounts for endogenous input parameters (Geissmann \& Ponta, 2017). A Monte-Carlo simulation showed that a correlation between input parameters had a significant effect on the outcome. The authors also discussed the role of hyperbolic discounting options, in which time preference rates decrease over time. However, the authors simply applied $8.25 \%$ of WACC for nuclear power and $7 \%$ for gas turbines during the whole project period.

In another paper, Tran et al. (2018) proposed incorporating the carbon price into the traditional LCOE formula to address emission penalties (Tran \& Smith, 2018). A Monte-Carlo method can be utilized to perform global sensitivity analysis, which comprises four steps: interpreting distributions of input variables, generating random values based on the distributions, computing the LCOE with the input values, and aggregating the LCOE result. The discount rate in their study was part of the stochastic model and assumed a range of $3 \%$ to $10 \%$. Their study is meaningful in that it considered a carbon price in the LCOE comparison via a probabilistic Monte-Carlo approach.

Lee et al. (2020) also applied a stochastic approach to estimate the LCOE for solar photovoltaic (PV) in South Korea (Lee \& Ahn, 2020). They tried to derive a realistic analysis result by using actual data generated from solar PV projects. They also treated the discount rate itself as a variable with a $4.5 \%$ to $7.5 \%$ range of triangular distribution. They suggested that the discount rate was the second most critical factor, accounting for $18 \%$ of the variance in the LCOE estimation.

In the present article, we introduce a different perspective of economic theory to reflect project risk, directly corresponding to costs in calculating the LCOE, which may contribute a step forward from the previous researches. However, our probabilistic methodology of estimating risk equivalent LCOE derives from the previous researches.

\section{Research Methodology}

First, we review theories to propose an alternative way to reflect project risk in the LCOE formula. We calculate the LCOE of geothermal technology both with traditional formula and alternative certainty equivalent model based on the same data. The former is a deterministic model using a risk-adjusted discounting approach; the latter is probabilistic and reflects risk directly to the expected cash flow(cost) of the LCOE. Next, we conduct a simulation analysis based on the variation in the risk level of critical variables based on the certainty equivalent LCOE model. We compare the simulation result to that of a traditional LCOE to draw implications. 


\subsection{Theoretical Background}

\subsubsection{Risk-Adjusted Discount LCOE (LCOE $\left.E_{R A D}\right)$}

Although there is much variation in the LCOE equation, a highly representative metric may be:

$$
\operatorname{LCOE}_{R A D}=\left(\sum_{t=1}^{n} \frac{\left(C_{t}+O_{t}+V_{t}\right)}{\left(1+R_{R A D}\right)^{t}}\right) /\left(\sum_{t=1}^{n} \frac{E_{t}}{\left(1+R_{R A D}\right)^{t}}\right)
$$

Where $t$ is the timing of cost or energy generation of the project's duration of $n ; C_{t}$ is the capital and decommissioning cost in period $t ; O_{t}$ is the fixed operating cost in period $t ; V_{t}$ is the variable operating cost in period $t ; E_{t}$ is the energy generated in period $t ; R_{R A D}$ is the risk-adjusted discount rate. This formula considers costs over the life of a project, deriving a lifetime cost per unit of energy (Aldersey-Williams \& Rubert, 2019).

We name the traditional $L C O E$ equation (1) as ' $L C O E_{R A D}$ ' and discount rate $R$ as ' $R_{R A D}$ ' to distinguish them from the alternative model, which is based on the 'certainty equivalent' approach. We calculate the $L C O E_{R A D}$ of geothermal technology case based on the equation (1).

A risk-adjusted discount rate $\left(R_{R A D}\right)$ is needed to derive the $L C O E_{R A D}$, which is traditionally set as something around the weighted average cost of capital (WACC) from comparable projects or industry averages. Conceptually, it includes time value discounting and risk discounting portion together with debt financing cost, rarely matching with the proper level of specific project risk. As a result, it does not always lead to the right decision (Zhang, 2010). In particular, it is not theoretically appropriate to apply WACC to discount purely negative cash flows $\left(C_{t}+O_{t}+V_{t}\right)$ in the LCOE numerator. However, we searched benchmarking discount rates for geothermal technology to calculate the $L C O E_{R A D}$.

\subsubsection{Certainty Equivalent LCOE ( $\left.L C O E_{C E}\right)$}

Another way of considering risk is to use a certainty equivalent and discounting with a risk-free rate. Previous studies on certainty equivalent theory include works by Hennessy et al. (2006), Eeckhoudt et al. (1996), Gollier and Pratt (1996), Kimball (1993), Becker and Sarin (1987), and Gordon (1986). The definition of certainty equivalent is "a guaranteed cash flow that we would accept instead of an uncertain cash flow" (Damodaran, 2012). The concept of the certainty equivalent model stems from the expected utility theory. And the 'Fourfold Pattern' by Kahneman (2011) also explains people fear of loss (risk-averse) and tend to accept a less favorable settlement than the expected value when losses are expected with a low level of probability (Kahneman et al., 2011). It is consistent with the reason that people pay more for insurance or construction bonds than for an expected loss. Risk-averse people would accept a lower value of the certainty equivalent than the expected value from a given set of uncertain cash flows. The difference between the expected value and certainty equivalent equals the risk premium that risk-averse people are willing to pay to eliminate a given set of uncertainty.

Conceptually, the relationship between risk adjusted discount, where CAPM is used, and the certainty equivalent model can be shown with one-year valuation example as below:

$$
E(V)=\frac{E\left(C F_{1}\right)}{1+\left[R_{f}+\left(E\left(R_{m}\right)-R_{f}\right) \beta\right]}=\frac{E\left(C F_{1}\right)-E(V)\left(E\left(R_{m}\right)-R_{f}\right) \beta}{1+R_{f}}=\frac{C E\left(C F_{1}\right)}{1+R_{f}}
$$

where, $\mathrm{E}\left(\mathrm{CF}_{l}\right)$ is an expected cash flow at year one, $R_{f}$ is a risk free rate, $E\left(R_{m}\right)$ is an expected market return, $\beta$ is a systematic risk, and $C E\left(C F_{1}\right)$ is a certainty equivalent of $C F_{1}$.

In the equation (2), the $E(V)\left(E\left(R_{m}\right)-R_{f}\right) \beta$ is a Risk Premium $(R P)$ that investor is willing to sacrifice to get rid of the uncertainty. So, the certainty equivalent can be expressed as an expected cash flow $\left(\mathrm{E}\left(\mathrm{CF}_{l}\right)\right)$ minus risk premium (RP). As a matter of course, the Risk Premium (RP) changes in different times of cash flows due to a compounding effect.

Applying the equation (2), we can conceptually define the Certainty Equivalent LCOE (LCOE $\mathrm{CE}$ ) equation as follows: 


$$
L C O E_{C E}=\left(\sum_{t=1}^{n} \frac{E\left(C_{t}+O_{t}+V_{t}\right)+R P\left(C_{t}+O_{t}+V_{t}\right)}{\left(1+R_{f}\right)^{t}}\right) /\left(\sum_{t=1}^{n} \frac{E\left(E_{t}\right)-R P\left(E_{t}\right)}{\left(1+R_{f}\right)^{t}}\right)=\left(\sum_{t=1}^{n} \frac{C E\left(C_{t}+O_{t}+V_{t}\right)}{\left(1+R_{f}\right)^{t}}\right) /\left(\sum_{t=1}^{n} \frac{C E\left(E_{t}\right)}{\left(1+R_{f}\right)^{t}}\right)
$$

In the equation (3), the $C_{t}, O_{t}, V_{t}, E_{t}$ are no more constant numbers but variables that have uncertainty. And so, the risk premiums of all variables are deducted to achieve the certainty equivalents. A noteworthy point is the numerator part, which is comprised of costs $\left(C_{t}+O_{t}+V_{t}\right)$. They are negative cash flows, and thus the absolute value increase when we deduct risk premium. However, the quantity of energy generated $\left(E_{t}\right)$ in denominator portion decreases in value when risk premium is deducted.

For the purpose of estimating the $\mathrm{LCOE}_{\mathrm{CE}}$ in equation (3), we will apply a probabilistic approach based on Monte-Carlo simulation because a mathematical calculation may incur several problems. First of all, the mathematical approach needs an assumption of independency among the risk premiums in variables $\left(C_{t}, O_{t}, V_{t}\right.$, $\left.E_{t}\right)$. Second, we need to know the value of $\mathrm{LCOE}_{\mathrm{CE}}$ to calculate the Risk Premium (RP), which brings a circular problem. Third, we can't get systematic risk $(\beta)$ for individual variables $\left(C_{t}, O_{t}, V_{t}, E_{t}\right)$. On the other hand, the probabilistic approach with Monte-Carlo Simulation can provide a practical solution to calculate the certainty equivalent value as well as risk premium under a statistical reliance level.

Figure 1. The quasi-certainty equivalent under probabilistic approach

As there exists no 'completely certain future value' in the real world, we use a quasi-certainty equivalent. In this paper, we define a certainty equivalent as 'the maximum critical value that cumulative probability under which point does not exceed a predetermined criterion $(\alpha \%)^{\prime}$ as illustrated in Figure 1. From the positive point of view, it also means the maximum critical value that we can suggest a mean value with (1- $\alpha \%$ ) of confidence level. A certainty equivalent of cost locates below the expected value, and thus it is the sum of expected value and risk premium in absolute numbers, which relation is shown in equation (3).

Let us define a sample space $\Omega$ of $\operatorname{cost}\left(C_{t}\right)$, represented by a set of $\mathbb{R}$. Assuming the $C_{t}$, be a probabilistic variable, we put a cumulative distribution function $(\mathrm{CDF})$ of $C_{t}$ as follows:

$$
F(x)=\int_{-\infty}^{x} p C_{t} d C_{t}=P\left(C_{t} \leq x\right)
$$

where, $F: \Omega \rightarrow[0,1], x \in \mathbb{R}$, and $P$ is the corresponding CDF. In any cases, the $\alpha<50 \%$ condition should be met to keep the assumption of risk averseness.

As a result, we can obtain the $\operatorname{CE}\left(C_{t}\right)$ and $\operatorname{RP}\left(C_{t}\right)$ formula under $(1-\alpha) \%$ of confidence level and $\alpha<50 \%$ condition as follows:

$$
\begin{gathered}
C E_{(1-\alpha)}\left(C_{t}\right)=-F^{-1}(\alpha) \\
R P_{(1-\alpha)}\left(C_{t}\right)=-F^{-1}(\alpha)-E\left(C_{t}\right)
\end{gathered}
$$

The certainty equivalents of $O_{t}, V_{t}$ will be measured in similar way to the equation (5).

However, that of $E_{t}$ should be in positive domain as follows:

$$
C E_{(1-\alpha)}\left(E_{t}\right)=G^{-1}(\alpha)
$$

where, $G(z)=P\left(E_{t} \leq z\right), G: \Omega \rightarrow[0,1], z \in \mathbb{R}$, and $P$ is the corresponding CDF.

\section{2. $L C O E_{C E}$ estimation and simulation}

The estimation process is similar to that of previous researchers using probabilistic approaches. For applications involving multiple risk factors that affect the LCOE with non-normality, it is necessary first to define the dynamics of the fundamental process, which is made using the EXCEL software. Second, the distribution data of input variables in geothermal technology are determined based on historical data. Third, $N$ sample paths are 
generated following the combined distribution of multiple variables with integrated probability. Finally, following the generated sample paths and hypothesized distribution function of variables, the value of the LCOE distribution function with the assigned probability is generated. We used the PALISADE software tool for the Monte-Carlo simulation process in drawing the LCOE distribution.

And we use a risk-free rate to discount both cost and quantity of energy because risk factors are directly incorporated in the cash flows. We also propose $L C O E_{C E}$ value different from previous researches which suggested the most probable value $(E(L C O E))$ as a result.

\section{Input Data}

For the empirical analysis, we researched technical input data, assuming a geothermal plant that has a $50 \mathrm{Mw}$ system size, double flash type technology steam, and 25 years of economic life (IRENA, 2018). The operational environment is also defined as a region with steam temperatures above 180 degrees centigrade. Life-cycle costs are categorized into capital expenditure, and operations and maintenance (O\&M) costs. The main risks associated with geothermal energy are exploration, resource sustainability, financing, completion date, operational, offtake, price, and political considerations. These risks lead to uncertainty in the LCOE of the geothermal plant (Magnus \& Victor, 2012).

We gather technical geothermal data mainly from the four public sources: International Renewable Energy Agency (IRENA) (IRENA, 2018), Energy Sector Management Assistance Program (ESMAP) (Magnus \& Victor, 2012), U.S. Energy Information Administration (EIA) (EIA, 2019), and the U.S. Department of Energy (EERE, 2012). All monetary values are converted into real prices as of 2018 (CoinNews, 2020). We researched the mean value as well as the distributions of the major input data. The mean value is used to calculate $\mathrm{LCOE}_{\mathrm{RAD}}$, and the distribution is used for the Monte-Carlo Simulation in estimating LCOE $\mathrm{CE}_{\mathrm{CE}}$.

The capital expenditure includes not only construction costs but also development expenses incurred during the initial stage. A geothermal project requires high initial capital expenditures such as exploration, well drilling, infrastructure to build a power plant, and steam field development. Based on the collected data, the mean value of capital expenditure is $3,729 \mathrm{USD} / \mathrm{kw}$ and ranges from 2,000 to $5,872 \mathrm{USD} / \mathrm{kw}$. We selected the PERT distribution for the capital expenditure because it can identify the most likely value and closely resembles a realistic probability distribution, which also fits closely with normal or lognormal distributions.

O\&M involves costs to run and maintain a geothermal plant and the steam fields that ensure the highest capacity factor possible. The O\&M costs also include broken or old equipment replacement, steam pipeline service, and replacement of nonproductive wells. However, geothermal technology rarely requires fuel cost and, thus, variable O\&M costs are assumed to be negligible. The O\&M costs vary among sites depending on the chemical structure of steam and brine as the geothermal fluid can be acidic and has the potential to corrode equipment. From the collected data, the mean value of annual O\&M cost is approximately $129 \mathrm{USD} / \mathrm{kW}$, and it varies from 75 to $224 \mathrm{USD} / \mathrm{kw}$. A pert distribution is also applied to O\&M costs.

The capacity factor is the actual operating capacity recorded over the duration of project time compared against the designed capacity of a unit at its maximum operation. We pick $90 \%$ of the average initial capacity factor with $0.5 \%$ of annual degradation, which caters to the reduction in steam output. The initial capacity factor ranges from $85 \%$ to $92 \%$. The distribution range is narrow, and we would like to place greater trust on the mean value; therefore, we assign a TRIANGLE distribution for the capacity factor.

A geothermal project requires extensive upfront costs in the early stages of the project before project viability can be confirmed. This uncertainty of the upstream process is the reason investors request steep returns as a countermeasure against the risk involved. We have selected $10.9 \%$ of real WACC as a reference discount rate based on the Geothermal Electricity Technology Evaluation Model (GETEM) (EERE, 2012). WACC is used in calculating the LCOERAD.

Table 1. Summary of input variables 


\begin{tabular}{|c|c|c|c|c|}
\hline Input variables & $\begin{array}{l}\text { Mean } \\
\text { value }\end{array}$ & $\begin{array}{c}\text { Range } \\
\text { (Standard } \\
\text { deviation) }\end{array}$ & Distribution & References \\
\hline $\begin{array}{c}\text { Capital Expenditure } \\
\text { (USD/kw) }\end{array}$ & 3,729 & $\begin{array}{c}2,000 \sim 5,872 \\
(0.00749)\end{array}$ & PERT & $\begin{array}{c}\text { (EERE, 2012; EIA, 2019; } \\
\text { IRENA, 2019; Magnus \& } \\
\text { Victor, 2012) }\end{array}$ \\
\hline $\begin{array}{c}\text { Annual O\&M Cost } \\
\text { (USD/kw) }\end{array}$ & 129 & $\begin{array}{l}75 \sim 224 \\
(0.00735)\end{array}$ & PERT & $\begin{array}{c}\text { (EERE, 2012; EIA, 2019; } \\
\text { IRENA, 2019; Magnus \& } \\
\text { Victor, 2012) }\end{array}$ \\
\hline $\begin{array}{c}\text { Capacity Factor } \\
(\%)\end{array}$ & 90 & $\begin{array}{c}85 \sim 92 \\
(0.00742)\end{array}$ & TRIANGLE & (EIA, 2020a; IRENA, 2017) \\
\hline $\begin{array}{l}\text { WACC } \\
\text { (in real \%) }\end{array}$ & 10.9 & N/A & N/A & (EERE, 2012) \\
\hline
\end{tabular}

\section{The Estimation Result}

\subsection{LCOE estimation}

The $\mathrm{LCOE}_{\mathrm{RAD}}$ is estimated at $6.90 \phi / \mathrm{kw}$ based on the equation (1) and the mean input values of Table 1 . The

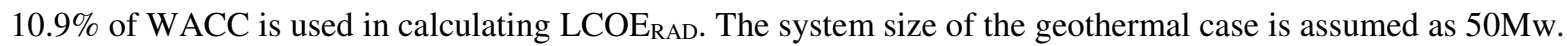

We performed Monte-Carlo Simulation with the distributions of inputs (Table 1) on top of the non-linear LCOE model to establish the probabilistic distribution of $\angle C O E$, which is defined by the equation (3) and (5). The result is illustrated as follows:

Figure 2. The distribution of $L C O E$ and $L C O E_{C E}$ estimation.

The Figure 2. is expressed in a reverse way to Figure 1 because the cost is entered as a positive number following the general industry practice. The most likely LCOE point estimation value, not reflecting risk, is estimated at $5.05 \mathrm{~s} \phi / \mathrm{kw}$. However, the CE values from the above distribution are selected following equation (5) and (7) with $90 \%$ and $95 \%$ confidence levels, both of which meet risk-averse conditions $(\alpha<50 \%)$ : the $\operatorname{LCOE}_{\mathrm{CE}}$ are estimated at $6.03 \mathrm{~s} \phi / \mathrm{kw}$ under $90 \%$ confidence level (P-90\%), and $6.29 \phi / \mathrm{kw}$ under $95 \%$ of confidence level (P-95\%). We used a 4.24\% risk-free rate, which is the average of a 20-year Treasury Bill of United States from 1998 to 2018, as a discount rate (FRED, 2020). The result implies that people with higher risk averseness will accept a higher risk premium; thus, the absolute number of CE in LCOE becomes larger, which is the 95\% of confidence level case. In other words, a risk-averse person tends to evaluate an uncertain cost as being larger than others. The $\mathrm{LCOE}_{\mathrm{RAD}}$ is estimated to be larger than the $\mathrm{LCOE}_{\mathrm{CE}}$ by $0.61 \not / \mathrm{kw}(8.8 \%)$. It could have led underinvestment if a policymaker relied on the $\mathrm{LCOE}_{\mathrm{RAD}}$.

After the Monte-Carlo simulation, we performed sensitivity analysis of the LCOE estimation result on major input variables, which result is illustrated in Figure 3. We found that construction cost variable has the greatest impact on the LCOE value followed by the operation cost and capacity factor variables. The blue bar indicates a positive proportional impact between independent (input) and dependent (LCOE) variables, and the red bar means the vice versa. The Figure 3. shows that capital expenditure and O\&M cost are positively correlated with LCOE, while the capacity factor is negatively correlated. Based on the most likely estimation value of $5.05 \notin / \mathrm{kw}$, if the capital expenditure increases one sigma the LCOE value will increase $1.07 \phi / \mathrm{kw}$, whereas if the capital expenditure decreases one sigma, the LCOE value will decrease $1.03 \phi / \mathrm{kw}$. When the O\&M cost increases one sigma the LCOE value will increase $0.67 \phi / \mathrm{kw}$, whereas if the O\&M cost decreases one sigma, the LCOE value will decrease $0.59 \phi / \mathrm{kw}$. In the case where the capacity factor increases one sigma the LCOE value will decrease $0.17 \phi / \mathrm{kw}$, whereas if the capacity factor decreases one sigma the LCOE 
value will increase by $0.24 ф / \mathrm{kw}$. Figure 4 . also shows the sensitivity of LCOE to the continuous changes in percentage.

Figure 3. Sensitivity of LCOE estimation on input variables (change in sigma)

Figure 4. Sensitivity of LCOE estimation on input variables (continuous changes in percentage)

\subsection{Scenario Analysis}

We created four scenarios by changing the degree of risk in three major variables: capital expenditure, O\&M cost, and initial capacity factor.

The first scenario analysis is to change the level of risk in capital expenditure, assuming all else being equal. The purpose of the analysis is to test how the $\mathrm{LCOE}_{\mathrm{CE}}$ changes due to the change of standard deviation in the capital expenditure $\left(\partial L C O E_{C E} / \partial \sigma(C a P e x)\right)$.

Figure 5. Scenario analysis: change of LCOE over the change of risk level in Capital Expenditure.

As is expected, the $\mathrm{LCOE}_{\mathrm{CE}}$ increases as the standard deviation of capital expenditures increase both at $90 \%$ and $95 \%$ confidence levels, as illustrated in Figure 5. The $\mathrm{Y}$-axis represents $\phi / \mathrm{kw}$, and the $\mathrm{X}$-axis represents the standard deviation of the capital expenditure. At the base point, where the standard deviation $\left(\partial L C O E_{C E}\right)$ is 0.74 , the $\operatorname{LCOE}_{\mathrm{CE}}(\mathrm{P}-95 \%)$ is $6.31 \phi / \mathrm{kw}$ and lower than the $6.90 \phi / \mathrm{kw}$ of $\mathrm{LCOE}_{\mathrm{RAD}}$. However, it grows over the LCOE to become $7.08 \notin / \mathrm{kw}$ when the standard deviation of capital expenditure reaches at 1.17 . The $\mathrm{LCOE}_{\mathrm{CE}}(\mathrm{P}-90 \%)$ becomes higher than $\mathrm{LCOE}_{\mathrm{RAD}}$ only when the standard deviation reaches at 1.39.

However, the $\mathrm{LCOE}_{\mathrm{RAD}}$ does not change in proportion to the increasing volatility of input variables because the mean values of input variables remain the same. If we were able to measure the accurate WACC, reflecting the increased risk of capital expenditure, we could have applied a revised WACC and obtained a similar result to $\mathrm{LCOE}_{\mathrm{CE}}$. However, it is difficult to adjust in response to the change of specific risk factors because benchmarking WACC is used. It also remains doubtful whether the increase in WACC accurately reflects the impact of project risk for the LCOE.

The second scenario analysis is to change the degree of risk in O\&M costs, assuming all else being equal. Through this analysis, we test how the change of standard deviation in the O\&M cost $\left(\partial L C O E_{C E} / \partial \sigma(O \& M)\right)$ effects on the $\mathrm{LCOE}_{\mathrm{CE}}$.

Figure 6. Scenario analysis: change of LCOE over the change of risk level in O\&M Cost.

Similar to the first scenario, $\mathrm{LCOE}_{\mathrm{CE}}$ increases as the standard deviation of O\&M costs increase at both $90 \%$ and $95 \%$ confidence levels, as illustrated in Figure 6 . At the base case, the standard deviation is 0.73 , and $\mathrm{LCOE}_{\mathrm{CE}}$ $(\mathrm{P}-95 \%)$ is $6.30 \notin / \mathrm{kw}$. However, when the standard deviation of O\&N costs rise to 1.08 , LCOE $\mathrm{CE}_{\mathrm{CE}}(\mathrm{P}-95 \%)$ goes over $\mathrm{LCOE}_{\mathrm{RAD}}$ and becomes $6.99 \mathrm{k} / \mathrm{kw}$. We could not identify where $\mathrm{LCOE}_{\mathrm{CE}}(\mathrm{P}-90 \%)$ exceeds $\mathrm{LCOE}_{\mathrm{RAD}}$.

The third scenario analysis is to change the risk level in capacity factor, assuming all else being equal. We test how the change in standard deviation in the capacity factor $\left(\partial L C O E_{C E} / \partial \sigma(C a P)\right)$ affects $L_{C O E}$.

Figure 7. Scenario analysis: change of LCOE over the change of risk level in Capacity Factor. 
Likewise, $\mathrm{LCOE}_{\mathrm{CE}}$ increases as the standard deviation of capacity factor increases at both $90 \%$ and $95 \%$ confidence levels, as illustrated in Figure 7. At the base case, the standard deviation is 0.74 , and $\mathrm{LCOE}_{\mathrm{CE}}(\mathrm{P}-95 \%)$ is $6.30 \% / \mathrm{kw}$. However, when the standard deviation of the capacity factor rises to $0.93, \mathrm{LCOE}_{\mathrm{CE}}(\mathrm{P}-95 \%)$ approaches $6.90 \notin / \mathrm{kw}$ of $\mathrm{LCOE}_{\mathrm{RAD}}$. We could not determine where $\mathrm{LCOE}_{\mathrm{CE}}(\mathrm{P}-90 \%)$ exceeds $\mathrm{LCOE}_{\mathrm{RAD}}$.

Finally, we test how $\mathrm{LCOE}_{\mathrm{CE}}$ changes, increasing the risk of the three factors simultaneously. As is illustrated in Figure 7, $\mathrm{LCOE}_{\mathrm{CE}}$ increases, and the slope is steeper than all of the previous analyses. When the standard deviation of capital expenditure, O\&M, and capacity factor are $0.92,0.86$, and 0.76 respectively, $\mathrm{LCOE}_{\mathrm{CE}}(\mathrm{P}-$ $95 \%)$ arrives at $6.92 \phi / \mathrm{kw}$, exceeding $\mathrm{LCOE}_{\mathrm{RAD}}$. $\mathrm{LCOE}_{\mathrm{CE}}(\mathrm{P}-90 \%)$ also arrives at $7.00 \phi / \mathrm{kw}$, exceeding $\mathrm{LCOE}_{\mathrm{RAD}}$, when the standard deviation of capital expenditure, O\&M, and capacity factor are 1.07, 0.99, and 0.80, respectively. We infer that the combination of individual risk enlarges the total project risk, increasing the $\mathrm{LCOE}_{\mathrm{CE}}$ faster. However, $\mathrm{LCOE}_{\mathrm{RAD}}$ remains at the same level due to the constant level of mean value in all three factors.

Table 2. The change of LCOE over the simultaneous change of risk in three factors

\begin{tabular}{cccccc}
\hline \multirow{2}{*}{ Scenario } & \multicolumn{3}{c}{$\begin{array}{c}\text { Standard deviation } \\
\text { of Capital Expenditure }\end{array}$} & $\begin{array}{c}\text { LCOEcE }(\mathbf{P}-95 \%) \\
\mathbf{c} / \mathbf{k w}\end{array}$ & $\begin{array}{c}\text { LCOEcE (P-90\%) } \\
\mathbf{c} / \mathbf{k w}\end{array}$ \\
& CaPex & O\&M & CaP & 6.31 & 6.03 \\
\hline 1 & 0.749 & 0.735 & 0.742 & 6.46 & 6.17 \\
2 & 0.793 & 0.775 & 0.749 & 6.69 & 6.35 \\
3 & 0.851 & 0.810 & 0.760 & 6.92 & 6.53 \\
4 & 0.925 & 0.863 & 0.768 & 7.18 & 6.74 \\
5 & 0.997 & 0.914 & 0.793 & 7.52 & 7.00 \\
6 & 1.076 & 0.990 & 0.809 & 7.86 & 7.28 \\
\hline
\end{tabular}

Figure 8. Scenario analysis: change of LCOE over the simultaneous change in capital expenditure, $\mathrm{O} \& \mathrm{M}$ cost, and capacity factor

\subsection{Discussion}

From the scenario analysis, we can see $\mathrm{LCOE}_{\mathrm{RAD}}$ does not change, although the uncertainty of the input variable increases. It is a limit of $\mathrm{LCOE}_{\mathrm{RAD}}$, which is based on the deterministic approach. Conversely, $\mathrm{LCOE}_{\mathrm{CE}}$ reflects the increasing level of risk at a specific input variable level. A more serious problem of LCOE RAD $_{\text {lies in }}$ discounting costs with WACC. The LCOE numerator comprises various costs, which is purely negative cash flow. In the case of negative cash flow, a higher WACC for risky projects generates lower present costs in absolute numbers, which the results suggest are a favorable condition. Thus, using a higher WACC for risky projects may mislead the evaluator.

If $\mathrm{LCOE}_{\mathrm{RAD}}$ is used without caution, it may lead policymakers in the wrong direction in terms of social resource allocation. In the base case from 5.1. LCOE estimation, where $\mathrm{LCOE}_{\mathrm{RAD}}$ is higher than $\mathrm{LCOE}_{\mathrm{CE}}$, policymakers might invest in geothermal technology less than is socially optimal. Alternatively, where $\mathrm{LCOE}_{\mathrm{CE}}$ should be evaluated as higher than $\mathrm{LCOE}_{\mathrm{RAD}}$ due to a specific risk expected from a target project from 5.2. Scenario Analysis, policymakers might invest in geothermal technology more than a social optimum. This possibility will be larger when the target project has either a higher or lower level of idiosyncratic risk than the industry average, especially if the geothermal technology has a higher deviation in project-specific risk.

Numerous previous studies have estimated the LCOE based on the probabilistic approach, using a MonteCarlo Simulation. However, the majority estimated the most probable value of the LCOE, which is conceptually 
the weighted average with an assigned probability. They also apply WACC to reflect project risk. Therefore, they are not free from the limit of $\mathrm{LCOE}_{\mathrm{RAD}}$, although they use a probabilistic approach. Some studies suggest that the confidence interval for the LCOE is an underestimated distribution. However, they may provide poorer results because the risk is double counted: originally discounted by WACC and again expressed by a range of confidence levels, reflecting the combined risk of input variables that should have been already included in the WACC.

As Gordon (1986) maintained, the certainty equivalent (CE) approach has several advantages over the riskadjusted discount rate (RADR) (Sick, 1986). First, the CE model allows for a separation of the risk adjustment from the time value discounting process, which can resolve various complex issues. Second, the beta used in the risk-adjusted discount rate method is an aggregate risk measure, which is the average of all cash flows in the firm measured from security-market data. We cannot find data for security that represents a pure type of project or a specific item of risk. Third, the multiplicative models using risk-adjusted discount rates are less tractable for changes in specific risk levels.

\section{Conclusion}

LCOE estimation is critical in supporting both policymakers and investors in key investment decisions or the determination of the most viable energy mix. However, the traditional method of calculating the LCOE cannot reflect the individual status of risk per variable because it depends on a deterministic method using WACC. The WACC does not apply a specific level of risk in a target project since it is approximated from comparable projects or industry averages. A serious potential pitfall lies in discounting series of project costs with WACC, which is a risk-embedded discount rate. As a result, making decisions based on the traditional LCOE method may result in a wrong investment decision due to poor evaluation of individual project risk. We propose the traditional method of LCOE should be used prudently, recognizing it can distort the calculation result more if the target project has a greater discrepancy of risk from the industry average.

We suggest LCOE $_{\mathrm{CE}}$ as an alternative LCOE estimation methodology in terms of risk consideration. We showed that this methodology could rationally reflect the risk of the individual input variable through scenario analysis. More importantly, we provide a theoretical background of risk formulation based on the utility theory as well as a probabilistic LCOE estimation methodology.

However, there are several limitations to this paper. First, the certainty equivalent is a theoretical value. Therefore, we introduced a quasi-certainty equivalent and its function with a designated confidence level ((1$\alpha) \%$ ). It is not possible to answer what percentage of confidence level is proper to identify the CE value in equation (5), which depends on the individual evaluator's risk preference. Second, the data set used in this study included only the U.S. market and not enough in number. Further research on data is required from different regions that have geothermal resources. The distribution curves used are arbitrary to some degree; therefore, more study is required on the appropriate form of the distribution curve. Third, the LCOE $_{\mathrm{CE}}$ methodology is cumbersome for practical usage. A realistic set of distribution data on major input variables is necessary and should be processed with a Monte Carlo Simulation tool. Additionally, some level of statistical knowledge is required to interpret the result. Finally, we argued that WACC could not accurately reflect risk when calculating LCOE based on previous literature, including Beedles (1978), Lewellen (1977), and Aswath (2007). However, we did not show the relation between discount rate and LCOE value. Further study is necessary for this topic.

\section{Abbreviations}

LCOE: Levelized Cost of Energy; WACC: Weighted Average Cost of Capital; U.S. EIA: United States Energy Information Agency; OECD IEA: Organization for Economic Cooperation and Development International Energy Agency; IRENA: International Renewable Energy Agency; LCOERAD: Risk-Adjusted Discount LCOE; LCOECE: Certainty Equivalent LCOE; CAPM: Capital Asset Pricing Model; $\partial L C O E_{C E} / \partial \sigma($ CaPex $)$ : $\operatorname{LCOE}_{C E}$ changes due to the change of standard deviation in the capital expenditure; $\partial L C O E_{C E} / \partial \sigma(O \& M)$ : change of $\mathrm{LCOE}_{\mathrm{CE}}$ due to the change of standard deviation in the O\&M cost; $\partial L C O E_{C E} / \partial \sigma(C a P)$ : change of $\mathrm{LCOE}_{\mathrm{CE}}$ due to the change in standard deviation of capacity factor; RADR: risk-adjusted discount rate. 


\section{List of symbols}

$t$ : timing of cost or energy generation of the project's duration of $n ; C_{t}$ : capital and decommissioning cost in period $t ; O_{t}$ : fixed operating cost in period $t$; $V_{t}$ : variable operating cost in period $t ; E_{t}$ : energy generated in period $t ; R_{R A D}$ : risk-adjusted discount rate; $E\left(C F_{1}\right)$ : expected cash flow at year one; $R_{f}$ : risk free rate; $E\left(R_{m}\right)$ : expected market return; $\beta$ : systematic risk; $C E\left(C F_{1}\right)$ : certainty equivalent of $C F_{1} ; R P$ : Risk Premium; $\Omega$ : a sample space of $\operatorname{cost}\left(C_{t}\right)$; $\mathbb{R}$ : set of natural numbers; CDF: Cumulative Distribution Function; O\&M: Operations and Maintenance; USD/kw: US dollar per kilowatt; $\varnothing / k w$ : cents per kilowatt.

\section{Acknowledgement}

Not Applicable.

\section{Author's Contributions}

A.L. and Soojin Park conceptualized and designed the study. A.L. collected and analyzed the data and wrote the empirical case analysis. Soojin Park and Yongbeum Yoon developed and wrote the theory and methodology section with an overall paper review. All authors have read and agreed to the published version of the manuscript.

\section{Funding}

This work was supported by the 2021 Research Fund of the KEPCO International Nuclear Graduate School (KINGS), Republic of Korea. (Funding number: not applicable).

\section{Availability of data and materials}

The datasets used and/or analyzed during the current study are available from the corresponding author on reasonable request.

\section{Competing Interests}

The authors declare they have no competing interest.

\section{References}

Aldersey-Williams, J., \& Rubert, T. (2019). Levelised cost of energy - A theoretical justification and critical assessment. Energy Policy, 124, 169-179. https://doi.org/10.1016/j.enpol.2018.10.004

Beedles, W. L. (1978). Evaluating Negative Benefits. The Journal of Financial and Quantitative Analysis, 13(1), 173-176. JSTOR. https://doi.org/10.2307/2330532

CoinNews. (2020). Current US Inflation Rates: 2009-2019. US Inflation Calculator. https://www.usinflationcalculator.com/inflation/current-inflation-rates/

Damodaran, A. (2007). Strategic Risk Taking: A Framework for Risk Management. Pearson.

Damodaran, A. (2012). Investment Valuation -Tools and techniques for Determining the Value of Any Asset (Third Edition). Wiley Finance.

EERE, (2012). Geothermal Electricity Technology Evaluation Model. Energy.Gov. https://www.energy.gov/eere/geothermal/geothermal-electricity-technology-evaluation-model

EIA, Cost and Performance Characteristics of New Generating Technologies, Annual Energy Outlook 2019.3.

EIA, (2020a). EIA - Electricity Data. https://www.eia.gov/electricity/monthly/epm_table_grapher.php?t=epmt_6_07_b

EIA, (2020b). Levelized Cost and Levelized Avoided Cost of New Generation Resources in the Annual Energy Outlook 2020. 5,22.

FRED, (2020). 20-Year Treasury Constant Maturity Rate. FRED, Federal Reserve Bank of St. Louis. https://fred.stlouisfed.org/series/GS20

Geissmann, T., \& Ponta, O. (2017). A probabilistic approach to the computation of the levelized cost of electricity. Energy, 124, 372-381. https://doi.org/10.1016/j.energy.2017.02.078

IRENA, (2018) Renewable power generation costs in 2018. 88.

IRENA, (2017) Renewable Power Generation Costs in 2017. /Publications/2018/Jan/Renewable-PowerGeneration-Costs-in-2017. /publications/2018/Jan/Renewable-power-generation-costs-in-2017

IRENA, (2019) Renewable Capacity Statistics 2019. https://www.irena.org/publications/2019/Mar/RenewableCapacity-Statistics-2019

IRENA, (International Renewable Energy Agency), \& Ruiz (IRENA), C. (2017). Geothermal Power: Technology Brief. 28.

Kahneman, D., Farrar, Straus, \& Groux. (2011). Thinking, Fast and Slow. New York. 
https://us.macmillan.com/thinkingfastandslow/danielkahneman/9780374533557/

Kolditz, O., Jakobs, L. A., Huenges, E., \& Kohl, T. (2013). Geothermal Energy: a glimpse at the state of the field and an introduction to the journal. Geothermal Energy, 1(1), 1. https://doi.org/10.1186/21959706-1-1

Laura Wendell, B., Thrainn, F., Ximena Rosio, H. R., Migara, J., John S., A., Stan, P., Juan Andres, T., \& Rivera Zeballos, S. A. (2018, November). Opportunities and Challenges for Scaling up Geothermal Development in LAC. http://documents.worldbank.org/curated/en/173681539626591426/Opportunities-and-Challenges-forScaling-up-Geothermal-Development-in-Latin-America-and-Caribbean-Region

Lee, C.-Y., \& Ahn, J. (2020). Stochastic Modeling of the Levelized Cost of Electricity for Solar PV. Energies, 13(11), 3017. https://doi.org/10.3390/en13113017

Lewellen, W. G., Lease, R. C., \& Schlarbaum, G. G. (1977). Patterns of Investment Strategy and Behavior Among Individual Investors. The Journal of Business, 50(3), 296-333. JSTOR. http://www.jstor.org/stable/2352539

Magnus, G., \& Victor, L. (2012). Geothermal Handbook: Planning and Financing Power Generation Geothermal Handbook: Planning and Financing Power Generation. ESMAP technical report;no. 002/12. World Bank, Washington, DC. (C) World Bank. https://openknowledge.worldbank.org/handle/10986/23712

Manzhos, S. (2013). On the Choice of the Discount Rate and the Role of Financial Variables and Physical Parameters in Estimating the Levelized Cost of Energy. International Journal of Financial Studies, 1(3), 54-61. https://doi.org/10.3390/ijfs1030054

Regenspurg, S., \& Schäfer, T. (2017). Workshop "Geothermal fluids in saline systems." Geothermal Energy, 5(1), 18. https://doi.org/10.1186/s40517-017-0076-x

Sick, G. A. (1986). A Certainty-Equivalent Approach to Capital Budgeting. Financial Management, 15(4), 2332. JSTOR. https://doi.org/10.2307/3665777

Sklar-Chik, M. D., Brent, A. C., \& de Kock, I. H. (2016). Critical review of the levelised cost of energy metric. South African Journal of Industrial Engineering, 27(4), 124-133. https://doi.org/10.7166/27-4-1496

The World Bank, ESMAP, \& DCID. (2014). Scaling-Up Renewable Geothermal Energy in Indonesia. http://documents.worldbank.org/curated/en/955541468148774504/pdf/893820ESM0P1300in0Indonesi a0KS15013.pdf

Tran, T. T. D., \& Smith, A. D. (2018). Incorporating performance-based global sensitivity and uncertainty analysis into LCOE calculations for emerging renewable energy technologies $\mid$ Elsevier Enhanced Reader. https://doi.org/10.1016/j.apenergy.2018.02.024

Zhang, Z. (2010). Certainty equivalent, risk premium and asset pricing. Frontiers of Business Research in China, 4(2), 325-339. https://doi.org/10.1007/s11782-010-0015-1 
Figures

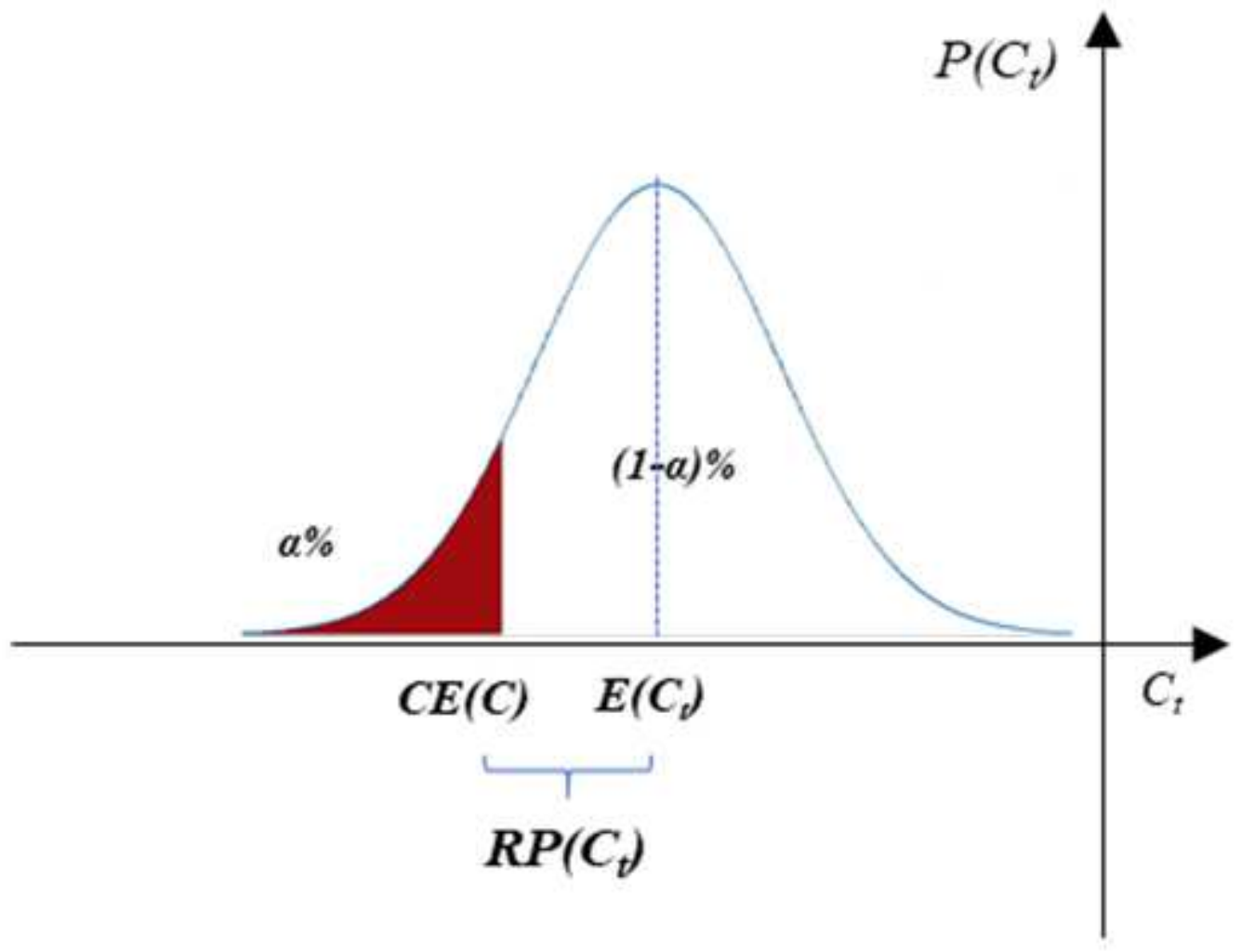

Figure 1

The quasi-certainty equivalent under probabilistic approach

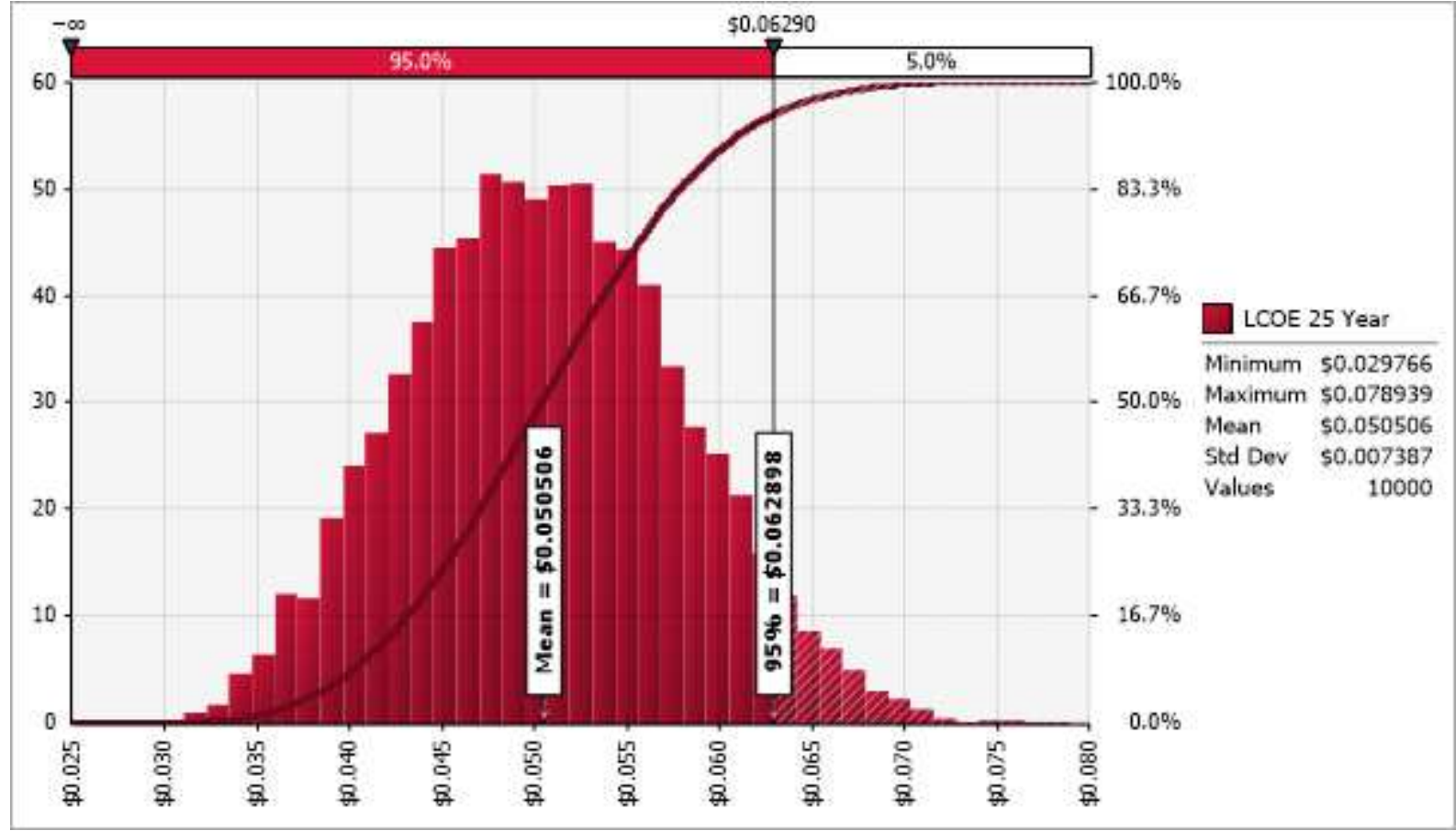

Figure 2 
The distribution of LCOE and LCOECE estimation.

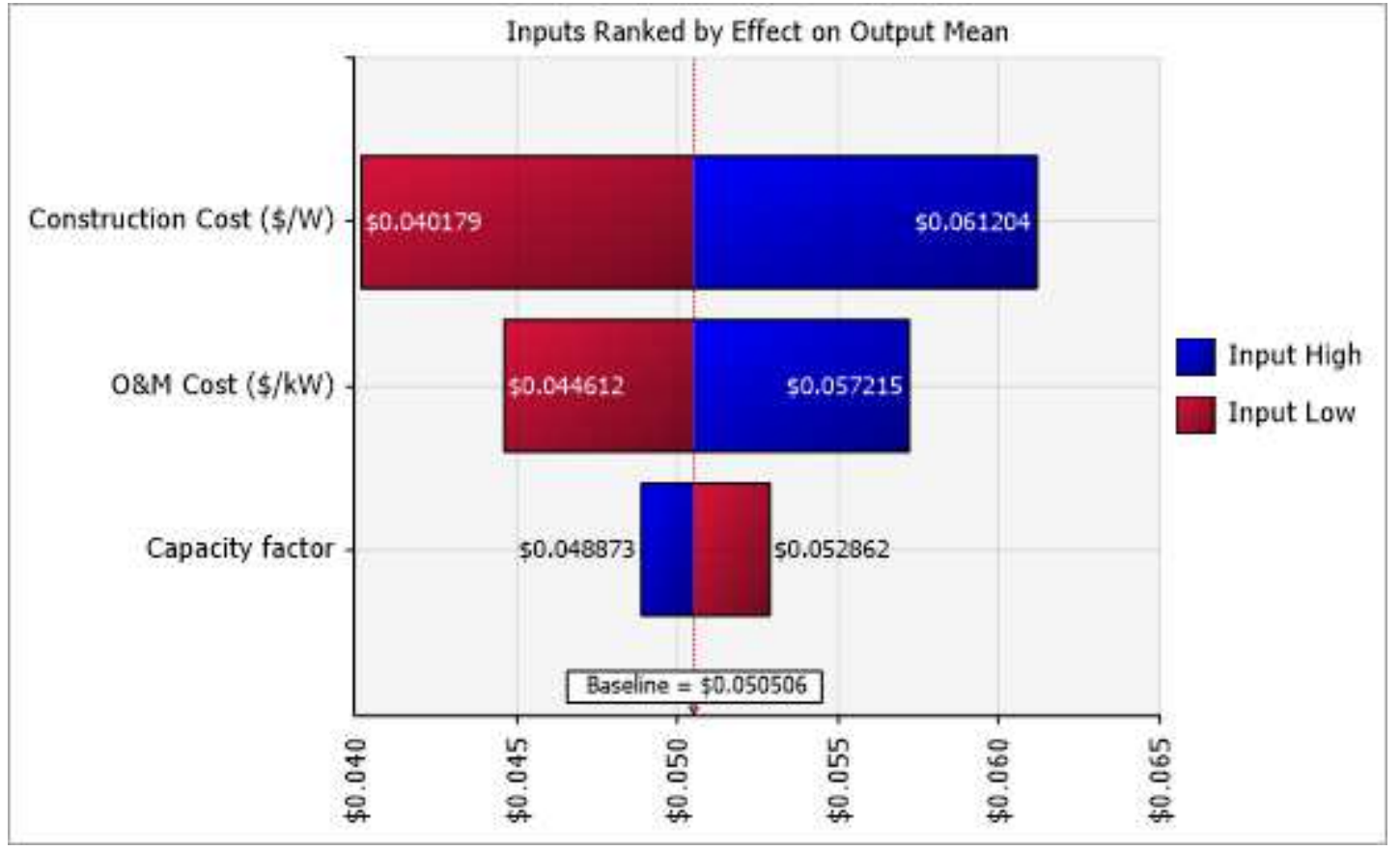

\section{Figure 3}

Sensitivity of LCOE estimation on input variables (change in sigma)

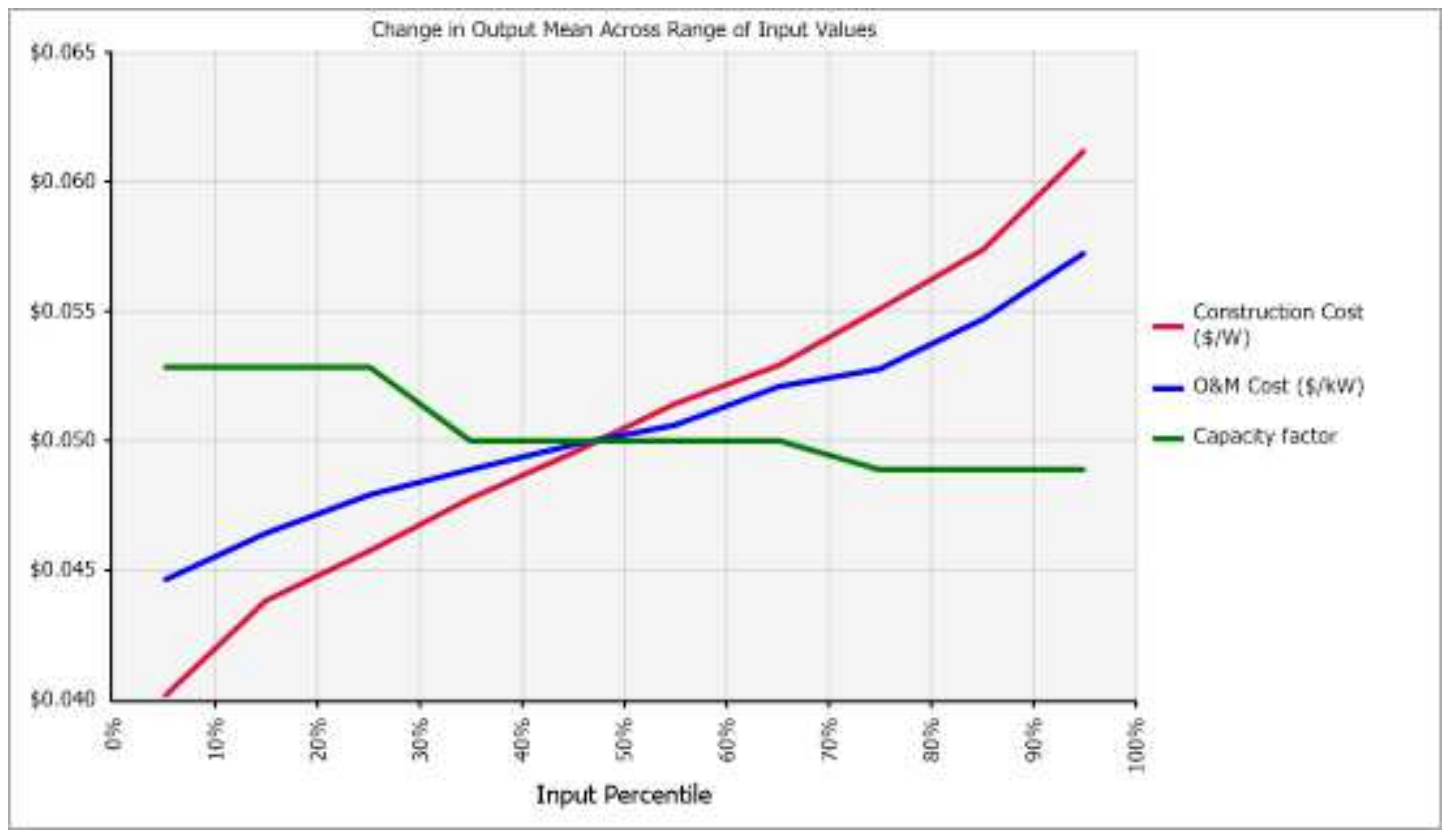

Figure 4

Sensitivity of LCOE estimation on input variables (continuous changes in percentage) 


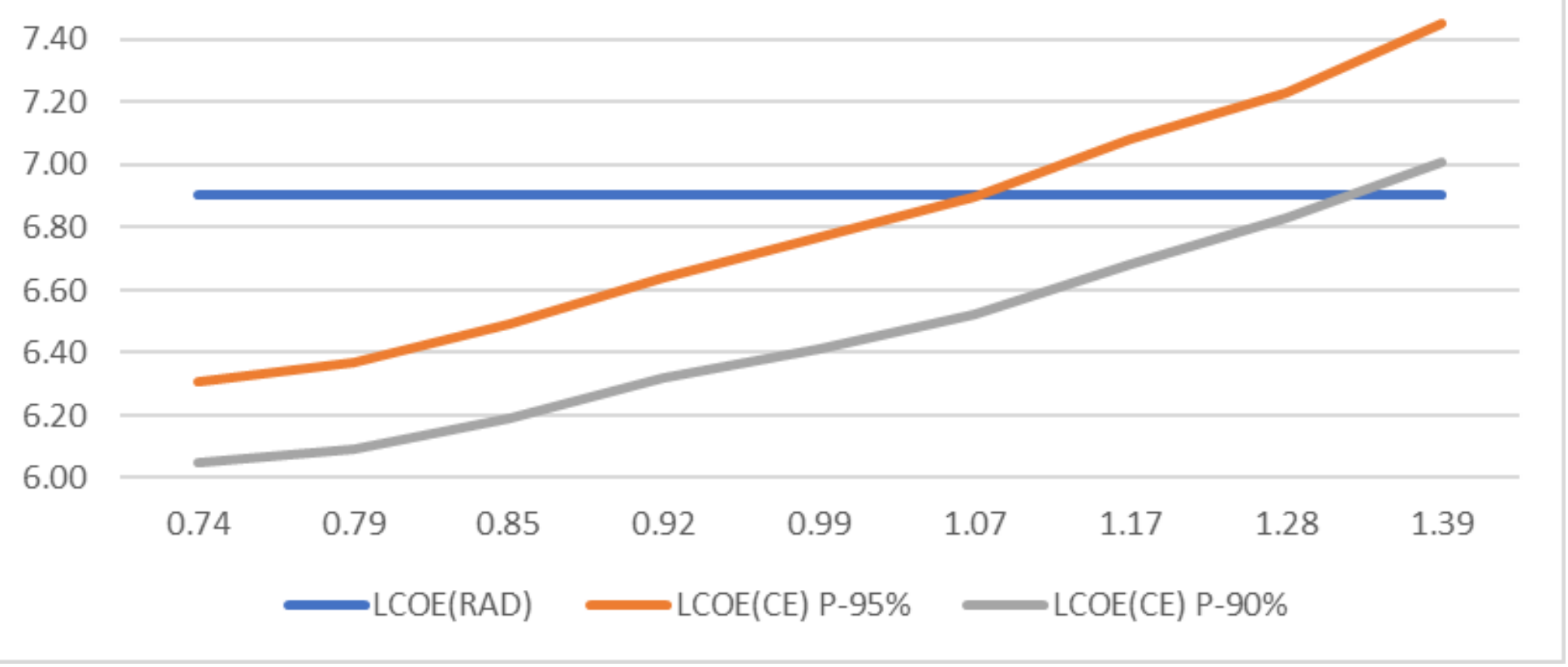

\section{Figure 5}

Scenario analysis: change of LCOE over the change of risk level in Capital Expenditure.

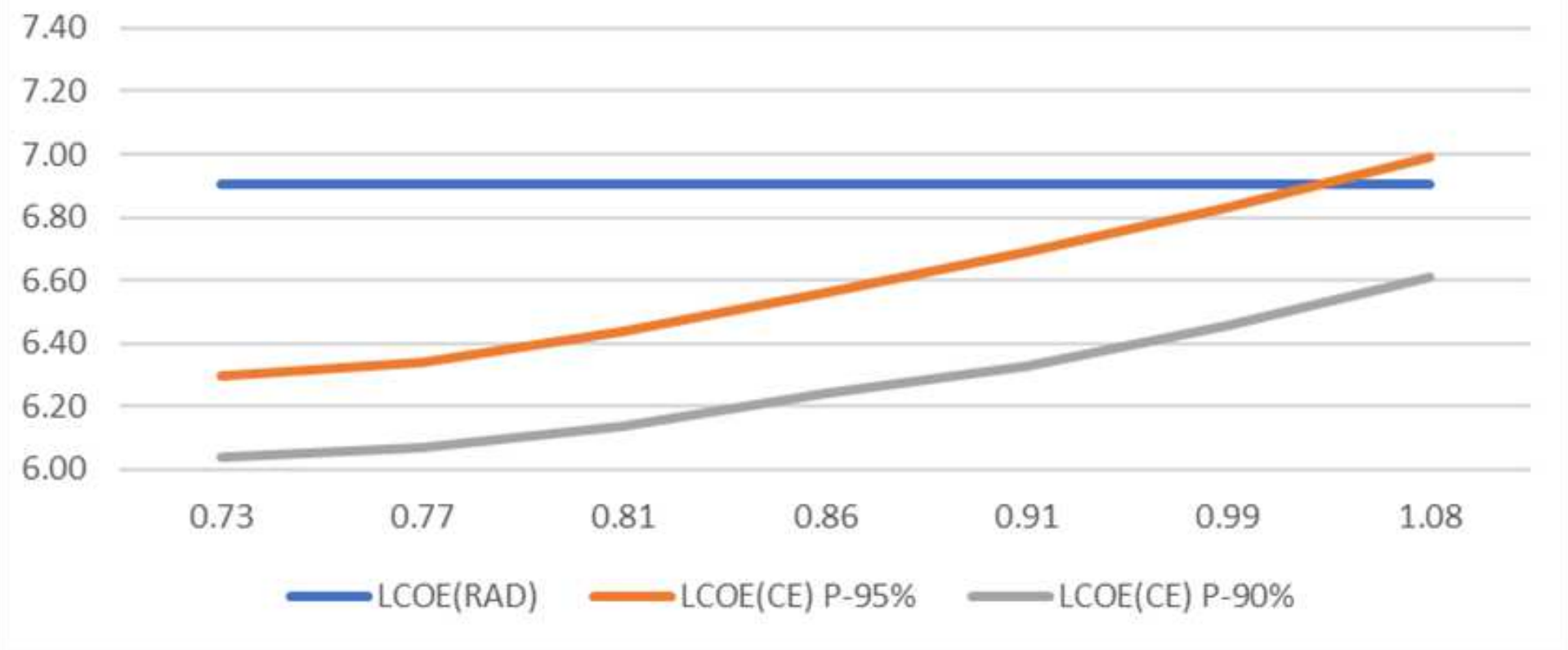

\section{Figure 6}

Scenario analysis: change of LCOE over the change of risk level in O\&M Cost. 


\subsection{0}

7.00

6.80

6.60

6.40

6.20

6.00
0.74
0.74
0.76
0.76
0.79
0.80
0.83
0.87
0.93
$\longrightarrow \mathrm{LCOE}(\mathrm{RAD}) \longrightarrow \mathrm{LCOE}(\mathrm{CE}) \mathrm{P}-95 \%=\mathrm{LCOE}(\mathrm{CE}) \mathrm{P}-90 \%$

\section{Figure 7}

Scenario analysis: change of LCOE over the change of risk level in Capacity Factor.

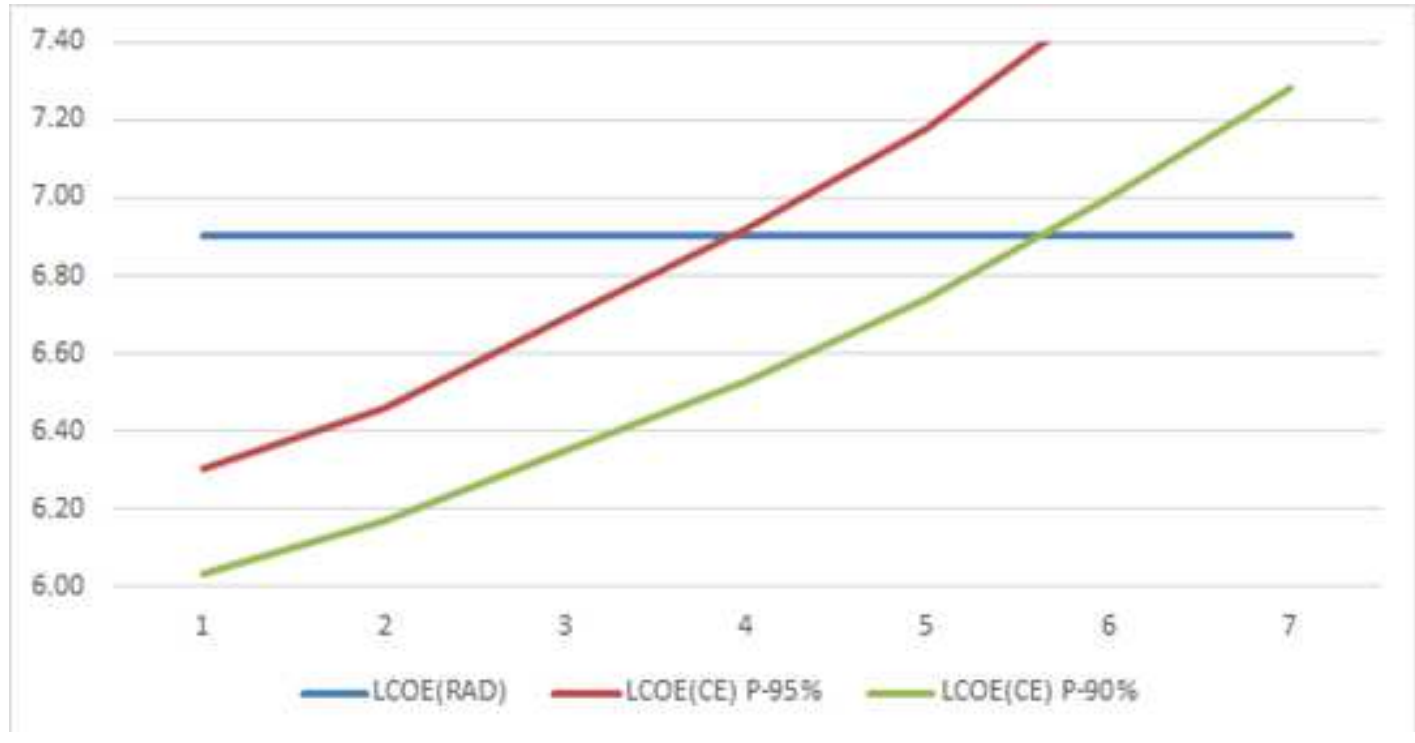

\section{Figure 8}

Scenario analysis: change of LCOE over the simultaneous change in capital expenditure, O\&M cost, and capacity factor 